\title{
INCLUDING UNIVERSAL DESIGN IN A SUMMER CAMP WORKSHOP ON ROBOTICS
}

\author{
Mireia Ribera, Eloi Puertas \\ Department of Mathematics and Computer Science, Universitat de Barcelona (SPAIN)
}

\begin{abstract}
In this paper we will describe a summer camp short-course intended for high-school students with excellent qualifications. The course is addressed to students who are thinking on studying a technical career including a section on universal design for the first time.

The department of Mathematics and Computer Science at Universitat de Barcelona will host a workshop on robotics next summer within the context of Campus Científicos de Verano by Fundación Española para la Ciencia y la Tecnología.. High-school students will be selected around Spain based on their qualifications and motivation to attend the workshop.
\end{abstract}

The first activity in the summer camp will be the building of Lego Mindstorms robots. These robots contain several sensors and actuators that can be programmed to do different tasks. One of the robots will be programmed to be able to track a line and another two will be programmed to do a Sumo fight on their own. Students will learn how to use sensors and actuators and code programming algorithms.

For the second activity the students will develop a Mobile App with the MIT App Inventor2 software [1] in order to control the robots. In this activity students will learn how to program apps in a simple way to complete their understanding of programming.

Taking into account European Higher Education Area requirements for Accessibility in technical careers, this workshop will introduce an innovation; the third activity will consist in the adaptation of the app and robots for multimodal access (including sound and sight redundant warnings) and the readjustment of the app's buttons for users with motor and visual disabilities (e.g. making the buttons bigger and with non-repeating behaviour).

Students attending the summer camp will be introduced to the needs and skills of different user profiles of people with disabilities. After this theoretical introduction, they will experience motor and visual disabilities with simulations inspired by the Inclusive design Toolkit resource [2] ]. And finally, they will modify the app based on IEEE RWEP Accessible apps by Ayanna Howard [3] so to maximise the accessibility possibilities of App Inventor. Complementary resources will be made available to those students showing interest in this area, such as RWEP prosthetic hands projects, other toolkits and bibliography.

This will serve as a first experience for the students and there is no prevision of including technical aids such as GRID2 or similar [4] due to budget restrictions. There are no students with disabilities registered for this year edition so the course does not seek accessibility for participants as authors. We will consider working on accessibility for participants of the following editions of this workshop, building on past experiences reaching this goal [5] [6] [7].

The main focus of the workshop is to encourage the creative learning of a robots summer camp [8], [9] with the inclusion of universal design as an essential requirement in the design and development of computer applications or systems. With this initiative we want to increase awareness on accessibility requirements for future technical students.

Keywords: robotics, accessibility, mobile apps.

\section{CONTEXT}

Nowadays, the syllabus in high school favours the interdisciplinary teaching of technology and sciences courses instead of treating them as independent subjects. This initiative is commonly coined with the term STEM [10] [11] [12], which is the acronym of the main disciplines being involved: Science, Technology, Engineering and Mathematics. The impact of new technologies in all the aspects of our society and the fact that new generations are digital native [13] ], have allowed this change in educational institutions and education policies. 
One clear example of the STEM philosophy is incorporating digital equipment in the class projects such as computers and also mobiles devices, robots... etc. Moreover, open source software and hardware have helped to break the economic barrier for acquiring such equipment in school institutions.

As a consequence, specialized activities, workshops and courses STEM-oriented using robots, mobile devices or prototyping platforms for children and teenagers have emerged in contexts such as summer camps. This is the case of the Scientific Summer Camp from Spanish Foundation for Science and Technology. Next July it will be the seventh edition of this campus, oriented to the growth of curiosity and interest in science and technologies among secondary school students. The total number of attendees is 1920 split between sixteen excellence campus colleges all around Spain. Students will work in different scientific projects headed by university professors and researchers.

In our case, the department of Mathematics and Computer Science at Universitat de Barcelona will embrace for two weeks two groups of 12 students from secondary schools coursing their second year.

\section{LEGO MINDSTORM AND MIT APPINVENTOR AS LEARNING PLATFORMS FOR KIDS}

Lego Mindstorm [14] is a robotic platform developed by the famous Danish toy company Lego. This platform adds microcontrollers and sensors to the well-known Lego bricks structures. The electronic part was developed by MIT at the beginning, aiming to introduce kids in programming and robotics [15]. In 2014 the third generation of Lego Mindstorm was launched. This new generation (EV3) introduces an enhanced microcomputer and set of sensors, making it possible to develop any kind of robotic or programming creation.

Building a robot is not a difficult task for teenagers, thanks to the friendly Lego bricks and the vast amount of building guides that help in the more complex part of mechanics (gears, motors, axes).

Moreover, thanks to a very easy visual programming language, even kids can programme their own robots. One example of it is the FIRST Lego league, where kids from 8 years old from the entire world compete among them solving complex challenges using Lego Mindstorms.

Another successful way to teach programming to kids is by mobile Apps means. New generations in our society have an early contact with mobile phones and tablets and they know how to use them. The possibility to create their own applications and games motivates them to learn programming skills.

MIT APPInventor2 [1] is an online visual programming platform that allows kids to create mobile Apps for Android. It uses visual blocks for developing the program, similar to puzzle pieces (in a similar way to Scratch [16] and StartLogo [17]). The workflow for building the App has two main phases. On the first phase, the design of the App is modelled by drag-and-drop User Interfaces (UI) widgets to a mobile device screen. On this first step, all the interactive elements in the App are arranged within the mobile screen. After this step, another display allows to add logical behaviour to these elements. This behaviour is done using a kind of puzzle pieces that represent classical flow structures such as loops, conditionals, subroutines, procedures, logical and arithmetical operations, etc. Therefore, the instructions are pieces that fit together one below or inside the other only if they are semantically allowed.

Besides these typical programming blocks, MIT App Inventor offers a set of blocks to interact with mobile devices elements such as gyroscope, cam, Bluetooth... Furthermore, it has a set of blocks to command Lego Mindstorms robots via a Bluetooth connection.

The use of this tool has become very popular in schools and high schools, but also among hobbyists. As on December 2015, MIT Applnventor 2 had 140k weekly active users and 4 million registered users in 195 countries, and a total of 12 million built applications.

\subsection{Summer Camp Robotics and Mobile Devices Workshop}

The workshop we provide in the scientific summer camp, attempts to engage boys and girls into programming combining these two different platforms. The workshop is divided in four sessions, 3 hours each of them.

In the first session participants will get started with Lego Mindstorms pieces and software. Every team of students will have a last generation Lego Mindstorms box. As a first task, students will have to build 
a very simple robot with sensors and motors, following a construction guide. Once the robot is finished, the students will learn how to use the Mindstorm programming platform. They will start by programming very simple programs, where they will discover how to use sensors data, turn motors on and off, show information on screen, etc.

In the second session, students will have to solve two different tasks. The first task is to design a robot able to follow a black line drawn in a white sheet of paper without crossing it. Then, these robots will do a race in a table with two identical line traces. The robot arriving first to the finish line will be the winner of the race. The second task is to build a sumo robot. These robots will take part in a sumo competition. In this competition, robots are placed inside a circle and the winner is the one that can find and push the adversary out of the circle.

In order to solve these two problems, students will have to design the body of the robots using Lego pieces and the sensors and motors needed to solve the problem with the best results. Then they will have to program them. The programming approach taken here is reactive programming, i.e. a loop iterating over the sensors and the motors will act depending on the received data.

In the third session students will design a remote controlled robot using a mobile application developed by them. To achieve this goal, students will use MIT App inventor 2 . They will decide the user interface elements and how these elements will interact with the robot, thanks to the Lego Mindstorm NXT direct control blocks in the MIT App inventor toolbox.

In the last session students will adapt their robots and App for different user profiles. The rest of this paper explains in depth this aspect, which is a novelty in this type of robotic workshops.

At the end of the workshop, students will present their capstone project results to the rest of the summer camp participants.

\section{INNOVATION IN ACCESSIBILITY}

What we introduce in this paper is the inclusion of a section on universal design on a classic summer work camp on Lego robots. In section 3.1 we describe the new information given to participants, and in section 3.2 and 3.3 we describe the changes to the code task on robots and on Applnventor respectively.

\subsection{Different needs awareness}

In order to change the mind-set of students they will have to learn different users' needs and experience them too. We will prepare slides showing vision, dexterity and hearing functions and impact of limitations, related context-driven disabilities, prevalence for each and design guidance based on the inclusive design toolkit [2]. Slides will be created in an interactive way, and only after discussion a summary will be presented.

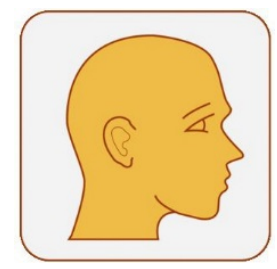

Fig. 1 User capabilities symbol in Inclusive Design Toolkit

After each user function description participants will simulate being the described user with the related impairment and they will have to fulfil some tasks in Applnventor.

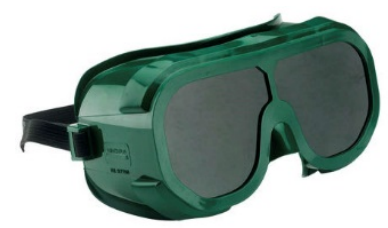

Fig. 2 Glasses

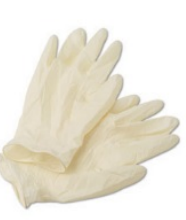

Fig. 3 Gloves 
With customized glasses simulating no central vision, no peripheral vision, retinophaty, and blurred vision, participants will have to login and create a new project in Applnventor. Afterwards, wearing three layers of disposable gloves they will have to create the buttons and fill in their names, and finally they will have to work for 2 minutes with the non-dominant hand (left for right-handed and right for lefthanded) and match different blocks in the application.

\subsection{APP Inventor - Accessibility design}

Following the ideas of Real World Engineering Projects "Accessible Apps: Decoding of the World for the Visually Impaired"[3] students will improve the design of the app taking into account:

- The needs of users with motor-impairments or low-vision: the font-size will be bigger, and the size of the buttons increased to avoid any problem in their identification and selection.

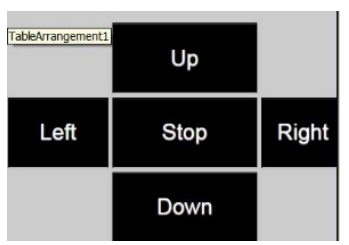

Fig. 4 Big buttons

- The needs of blind users. Every button will include a sound playing when it is selected. The sounds can be recorded by the students themselves or can be created online by any existing TTS free online application.

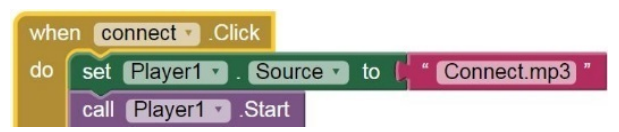

Fig. 5 Each control will have an audio associated

- The needs of users with low-vision. The initial colours of the app will be very contrasted and inverted (light text over dark background), and a new button will be created to invert the colours, as this user group includes different preferences.

\section{Connect}

Fig. 6 Control button with high contrast

\section{Stop}

Fig. 7 Movement button with high contrast

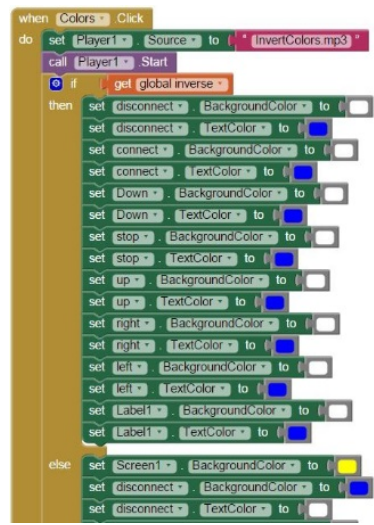

Fig. 8 Code to change colors upon "Inverted colors" control 
- The needs of people with dyslexia with a friendly dyslexia font

\subsection{Changes to MultiModal Robots}

We can make our robots MultiModal Robots without any significant modification to them. Since Lego Mindstorm EV3 brick includes an internal speaker and a set of LEDs beneath the action buttons we will use them in order to make our robot more accessible.

By programming we can change the pattern of colours and the duration of LEDs while turned on. Therefore, it will be possible to remark an action by the blinking of LED's with a certain colour code. For example, when an action is successfully carried on, the LED can light in green during a certain amount of time. On the other hand, if the action is not successfully carried on, a red blinking pattern light can be displayed.

The internal speaker can also be programmed, so it is very easy, using EV3 software to attach sound to each action the robot is taking. For example, if you program the robot to turn right you can add a sound or digitalized voice to it. If internal storage is not enough for storing all the digitalized voice files, the external SD card slot can be used to get more disk space.

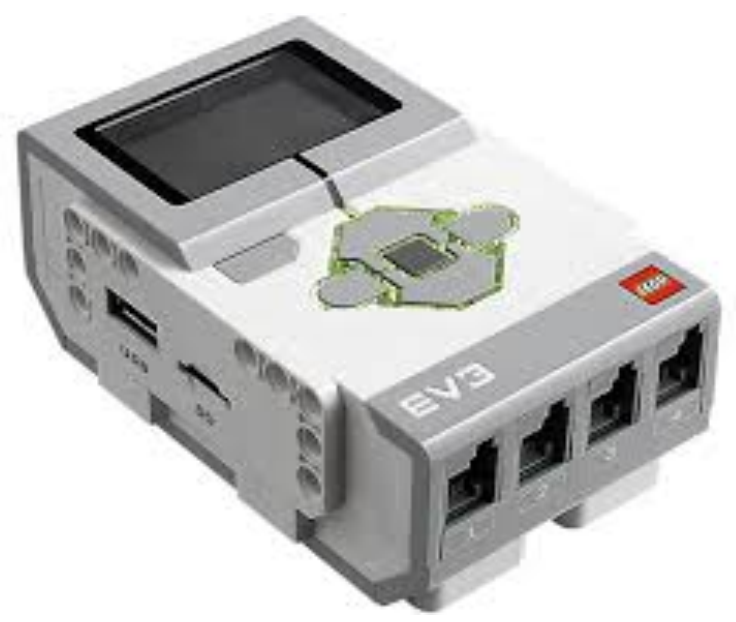

Fig. 9 EV3 Brick with leds turned on

\subsection{Complementary resources}

In order to accommodate different knowledge and motivation levels a web page with additional resources will be given for users to explore and experience. That will include English resources as well as Spanish resources for those whose English proficiency is not good enough.

\section{FUTURE RESEARCH}

This article describes an initial step towards including accessibility in a traditional robots training program. As a first experience, with low budget, there is no prevision of the inclusion of technical aids such as GRID2 or similar [4]. The initiative does not seek accessibility for participants as authors because there are no students with disabilities registered for this year edition.

After an evaluation of this initial experience our plans are to go further on this direction, including disabled users as participants of the summer camp, building on past experiences reaching this goal [5] [6] [7] [19] thanks to the collaboration with organizations supporting different disabled groups. For now, we are not considering other types of exclusion, such as breaking economical barriers in order to make the activity universally available [20].

\subsection{Indicators we will gather}

With this activity we pursue two main goals: to increase awareness of diversity in users, and thus the need to include flexibility in computer design; and to build the skills of new computer professionals who will include accessibility from the conception phase of a project. 
In order to evaluate the success of the project we will do a short survey among participants asking about knowledge acquisition and skills.

For any of your future designed products or applications, please answer briefly:

- K1. Are all users equal?

- K2. Which user groups do you have to take into account when designing a product?

- K3. Mention two interface solutions for two different user groups

Within the context of App MIT inventor, please answer briefly:

- K4. Whose fault is it if someone is not able to use an app?

- SK1. Are you able to set width, height and font-size of an actionable element of an app?

- SK2. Are you able to add audio to an actionable element of an app?

- SK3. Are you able to programmatically change colours of a screen element of an app?

- SK4. What else are you able to do in order to give more flexibility to your apps?

Within the context of Lego Mindstorm programming, please answer briefly:

- K5. What is a multimodal feedback?

- SK1. Are you able to include audio and light responses to a robot?

- SK2. Are you able to program more than a simultaneous answer from the robot?

Professors will record any question related to accessibility awareness raised by participants.

\section{DISCUSSION}

Spanish society and political landscape relating to accessibility is described, and final thoughts on educational benefits of the activity are exposed.

\subsection{Importance of accessibility in technical studies}

At a global level, some policy declarations particularly important are the definition of Universal Design [21], and the Convention on the Rights of Persons with Disabilities [22]. To enforce these principles the World Report on Disability[23] require and improvement in the training of human resources, and highlights the necessity of incorporating relevant education on the subject of disability into the current syllabus and credit programs.

In Spain, the awareness of the importance of universal design and diversity attention is low for professionals influencing career development as it can be seen in the low qualifications given to "Recognition of diversity and multiculturalism" skill in Libro Blanco on Computer Sciences Degree [24]. This skill was given the before-to-last priority of 19 skills proposed in surveys among companies, professionals and professors; this skill was categorized among Personal skills, and was also valued as of low importance.

Fortunately, the social perception is not aligned with legislation and policy. The first statement in the abovementioned Libro Blanco is that a Computer Scientist must be aware of the human, economic, social, legal and ethical implications of the profession. This document claims as the first goal of the Computer Science students to be able to specify, design, build, implement, verify, audit, evaluate and maintain computer systems responding to user needs.

Additionally, legislation in Spain covers also universal design. Particularly, Legislative Royal Decree $1 / 2013$, of the 29th of November [25], defines Universal Accessibility as the condition that must be met by environments, procedures, goods, products and services, as well as objects, instruments, tools and devices, to be understandable, usable and practicable for all in safety and comfort and in the most independent, natural way possible. This Decree states that "Education on "design for all" shall be included in the design of Professional Education degrees and the developing of the corresponding syllabus. In the university framework, additional provision 24 , section 5 , of Organic Law 4/2007 of the 12th of April, indicates that: "All study plans proposed by universities must take into account that training for any professional activities is to be conducted respecting and promoting Human Rights and the principles of universal accessibility and design for all." 
Therefore, the Conferencia de Rectores de las Universidades Españolas (Spanish University Principals Conference), has initiated the elaboration of some career guides to promote the inclusion of universal design principles to each career [26], even thought they have not reached yet Computer Science Engineering. Based on the [9], the guides aim at:

- To provide future professionals who will participate in the design of environments with a tool that will allow them to deal with any accessibility problems arising in their projects.

- To describe the current reality so students are aware of it and are able to be critical when it comes to assessing the pros and cons of a design.

- To define the application and involvement of Design for All in the different projects.

- To get future professionals to introduce Design for All, including it in their projects and final dissertations

\subsection{Combining creativity and empathy}

Embedding universal design in a regular teaching activity does not represent a cost in time or preparation [27] and improves the quality of learning since, the flexibility required by universal design makes products more sustainable. Taking into account that the interaction landscape will change dramatically during the following years, and diverse screens, interaction styles (touch, mouse, sight and audio) will be mainstream, students attending this seminar will be more prepared for their future design projects.

Understanding diversity and empathising with diverse needs through simulation activities and including it in the participants coding practices will improve the user centred approach of future products.

\section{REFERENCES}

[1] “MIT App Inventor 2." [Online]. Available: http://ai2.appinventor.mit.edu/\#5413363337396224. [Accessed: 18-May-2016].

[2] "Inclusive Design Toolkit Home." [Online]. Available: http://www.inclusivedesigntoolkit.com/betterdesign2/. [Accessed: 18-May-2016].

[3] "IEEE Real World Engineering Projects." [Online]. Available: http://www.realworldengineering.org/index.php?page=project\&n=1\&project=20. [Accessed: 18May-2016].

[4] A. Encarnação, Pedro; Adams, Kim; Londral, "Cultural issues in implementing an integrated augmentative communication and manipulation assistive technology for academic activities," in ISAAC, 2014, no. July 2014, p. 5.

[5] S. L. Ludi, L. Ellis, and S. Jordan, "An Accessible Robotics Programming Environment for Visually Impaired Users," in Proceedings of the 16th International ACM SIGACCESS Conference on Computers \& Accessibility, 2014, pp. 237-238.

[6] A. M. Howard and H. W. Park, "Using Tablet Devices to Engage Children with Disabilities in Robotic Educational Activities," J. Technol. Pers. with Disabil., pp. 96-107, 2014.

[7] M. Kabátová, L'. Jašková, P. Lecký, and V. Laššáková, "Robotic activities for visually impaired secondary school children," in 3rd International Workshop, Teaching Robotics, Teaching with Robotics, 2012, pp. 22-31.

[8] J. Adams, S. Kaczmarczyk, P. Picton, and P. Demian, "Problem solving and creativity in engineering: conclusions of a three year project involving reusable learning objects and robots," Eng. Educ., vol. 5, no. 2, pp. 4-17, 2010.

[9] E. Gandy, S. Bradley, D. Arnold-Brookes, and N. Allen, "The use of LEGO Mindstorms NXT Robots in the Teaching of Introductory Java Programming to Undergraduate Students," Italics, vol. 9, no. February 2016, pp. 2-10, 2010.

[10] “Governor's Task Force on K- ITEM Education," New Hampshire, 2015. 
[11] K. Howe, Christine; Luthman, Stefanie; Riga, Fran; Taber, "Didactic principles for STEM education: Forces and proportional relations in lower-secondary classrooms," in ECER 2011, Urban Education, 2011.

[12] H. B. Gonzalez and J. J. Kuenzi, "Mathematics ( STEM ) Education : A Primer," 2012.

[13] M. Prensky, "Digital Natives, Digital Immigrants," Horiz., vol. 9, no. 5, pp. 1-6, 2001.

[14] "Home - LEGO® MINDSTORMS® - LEGO.com - Mindstorms LEGO.com." [Online]. Available: http://www.lego.com/en-us/mindstorms/. [Accessed: 18-May-2016].

[15] "History - Mindstorms LEGO.com." [Online]. Available: http://www.lego.com/enus/mindstorms/history. [Accessed: 18-May-2016].

[16] "Scratch - About." [Online]. Available: https://scratch.mit.edu/about/. [Accessed: 18-May-2016].

[17] M. Colella, V., Klopfer, E., \& Resnick, Adventures in Modeling: Exploring Complex, Dynamic Systems with StarLogo. Teachers College Press, 2001.

[18] R. Klopfer, E., Scheintaub, H., Huang, W, Wendel, D., Roque, "The Simulation Cycle Combining Games, Simulations, Engineering and Science Using StarLogo TNG," J. E-Learning Digit. Media, vol. 6, no. 1, pp. 71-96, 2009.

[19] "Robotics Track at Youth Slam: A Promising Practice in Engaging Students with Visual Impairments | The Alliance for Access to Computing Careers." [Online]. Available: http://www.washington.edu/accesscomputing/robotics-track-youth-slam-promising-practiceengaging-students-visual-impairments. [Accessed: 18-May-2016].

[20] J. C. Gallagher, R. F. Drushel, and D. Bolick, "Increasing Accessibility to a First-Year Engineering Course in Mobile Autonomous Robotics," in American Society for Engineering Education Annual Conference and Exposition, 2005, p. 16.

[21] "What is Universal Design / Centre for Excellence in Universal Design." [Online]. Available: http://universaldesign.ie/What-is-Universal-Design/. [Accessed: 18-May-2016].

[22] United Nations, "Convention on the rights of persons with disabilities," 2006.

[23] WHO, "World report on disability," 2011.

[24] Aneca, Libro blanco título de grado en ingeniería informática. Madrid: Agencia Nacional de Evaluación de la Calidad y Acreditación, 2005.

[25] M. D. E. Sanidad and S. S. E. Igualdad, "Boletín oficial del estado," pp. 95635-95673, 2013.

[26] "CRUE - Formacion-Curricular-Diseno-para-todas-las-personas." [Online]. Available: http://www.crue.org/SitePages/Formacion-Curricular-Diseno-para-todas-las-personas.aspx. [Accessed: 18-May-2016].

[27] C. O. Leary and D. Gordon, "Universal Design , Education and Technology Universal Design , Education and Technology," in 9th IT\&T Conference, 2009. 